\title{
Evaluation of overall equipment effectiveness based on market
}

\author{
Farhad Anvari and Rodger Edwards \\ School of Mechanical, Aerospace and Civil Engineering, The University of Manchester, \\ Manchester, M60 1QD, United Kingdom
}

\begin{abstract}
Andrew Starr
School of Aerospace, Automotive and Design Engineering, The University of Hertfordshire, Hertfordshire, AL10 9AB, United Kingdom
\end{abstract}

\begin{abstract}
Purpose: Continuous manufacturing systems used within the steel industry involve different machines and processes which are arranged in a sequence of operations in order to manufacture the products. The steel industry is generally a capital-intensive industry and because of high capital investment, equipment utilization as effectively as possible is of high priority. This paper illustrates a new method, Overall Equipment Effectiveness-Market Based (OEE-MB) for the precise calculation of equipment effectiveness for full process cycle in order to respond to the steel market.

Design/methodology/approach: A refinement of the existing concept of OEE is developed based on a new scheme for loss analysis within market time. The paper illustrates the concept with a case study based on compact strip manufacturing processes within the steel industry.

Findings: While, the results for OEE by ignoring a considerable amount of possible hidden losses might be satisfying, the OEE-MB report shows potential room for improvement. It reflects changes in both internal and external market for the steel industry, and therefore provides a tool for not only monitoring but also managing improvement.

Practical implications: OEE-MB provides a sound perspective on improvement of steel plants by taking into consideration all losses within market time for meeting both internal and external demands.

Originality/value: OEE-MB monitors production and measures the equipment effectiveness for full process cycle in order to meet the market. It makes communication more efficient and easier within the steel industry and may be used as a benchmark to achieve world-class standard.
\end{abstract}

Keywords: Effectiveness, Equipment, Market, Losses, Maintenance, Steel

Paper type: Research paper

\section{Introduction}

Companies have different ways of measuring their manufacturing performance in order to achieve and maintain a competitive edge in the market. Overall equipment effectiveness (OEE) is the key measure of both Total Productive Maintenance (TPM) and Lean Maintenance. The concept of OEE, introduced by Nakajima (1988), is being used increasingly in industry. It looks at the wider manufacturing aspects, not only the equipment availability and performance, but also the efficiency losses that result from rework and yield losses.

According to Tajiri and Gotoh (1992) the relationship between OEE and losses depends on equipment availability, their performance rates and the quality of the product. OEE monitors the actual performance of a machine relative to its performance capabilities under optimal manufacturing conditions. While OEE reveals equipment's hidden losses after loading time, a new method in the steel industry based on market factors can monitor all losses within duration of satisfying the needs of internal and external market. A method based on market factor to account interaction among equipment, capital and market parameters which are crucial for capital intensive industry. This model makes communications easier and more efficient for the steel industry 


\section{Literature review}

Tajiri and Gotoh (1992) classified major losses into six groups. Breakdown losses, setup and adjustment losses are downtime losses used to determine a true value for the availability of a machine. The third and fourth losses including minor stoppage and reduced speed losses are known as speed losses. They are used as a measure of performance rate of a given machine. Rework and yield losses are defined as quality losses that determine the quality rate for the equipment.

A considerable amount of literature has been published in relation to the definition of OEE and its various applications. For example, Dal et al.(2000) point out the OEE measure can provide topical information for daily decision making. Hansen (2001) describes OEE as a powerful production and maintenance tool for increasing profit. Bamber et al.(2003) discuss OEE as a total measure of performance and concluded that cross-functional team working is essential for its success. Like the measure of OEE, Peters(2003)has identified a measure for Overall Craft Effectiveness (OCE).According to OCE, the productivity of labour resources can be calculated as under:

$$
\text { OCE }=\text { craft utilization } \times \text { craft efficiency } \times \text { craft service quality }
$$

Although OEE as originally described by Nakajima (1988) is seen to be the fundamental measurement method for performance effectiveness, it still requires further modification in order to meet wider requirements. Raouf (1994) formulates a new metric by the allocation of weightings to the different factors in the OEE. He claims that factors affecting OEE are not equally important in all cases and various weightings should be established. Al-Najjar (1996-1999) applies a new approach, describing it as a logical chain of reasons for reduction in the performance efficiency. He suggests that OPE (Overall Process Effectiveness) as a modified version of OEE for measuring the technical effectiveness of a process. Ljungberg (1998) states that the definition of OEE does not cover all factors which reduce capacity utilisation. He also explains that this weakness gives an opportunity for production management to consider some of the losses, as not being their responsibility.

Others have developed refined measures. For example, Jeong and Phillips (2001) note that it is crucial for capital-intensive industry to be able to estimate equipment utilization accurately in order to cover all losses. Ron and Rooda (2005) show that OEE is not directed to machine itself but includes effects of the environment of equipment too. Nachiappan and Anantharaman (2006) suggest a model for evaluation of overall line effectiveness in a continuous product line with n number of machines. Gibbons (2006) demonstrates a method of improving OEE using a lean six sigma approach.

\section{Background to problem}

In a continuous manufacturing system, different machines and processes are arranged in sequence of operations to produce goods. The product of a machine could be used as input for a subsequent machine or/and delivered to external market. In the steel industry, the metal sheets and coils produced by a hot strip mill based on their technical specifications and market requirement could be delivered to external customer or to a cold roll mill for further processing. The principle applies to the output of the cold roll mill. The products could either be sold to external customers or processed in a following machine in order to make galvanized sheets. Galvanized sheets also have two paths to an external customer or to a following machine for making colour coated sheets. The amount of a product for each path depends on the market position of a manufacturing company, product specification and customer requirements.

While measuring equipment effectiveness precisely and utilising it as effectively as possible are crucial for the steel industry due to its high capital investment, OEE estimation only starts with losses during loading time and the estimate of losses excludes those before loading time. This weakness also gives an opportunity for the production management to consider some of the losses which are not their responsibility (Ljungberg, 1998). While OEE basically includes effects of the environment of equipment 
(Ron and Rooda, 2005) but no changes even considerable ones in the following machines or external market may effect on the amount of OEE. These have constrained the level of OEE application and its role to make communications easier and more efficient in the steel industry. The losses ignored by OEE are shown in Figure 1.

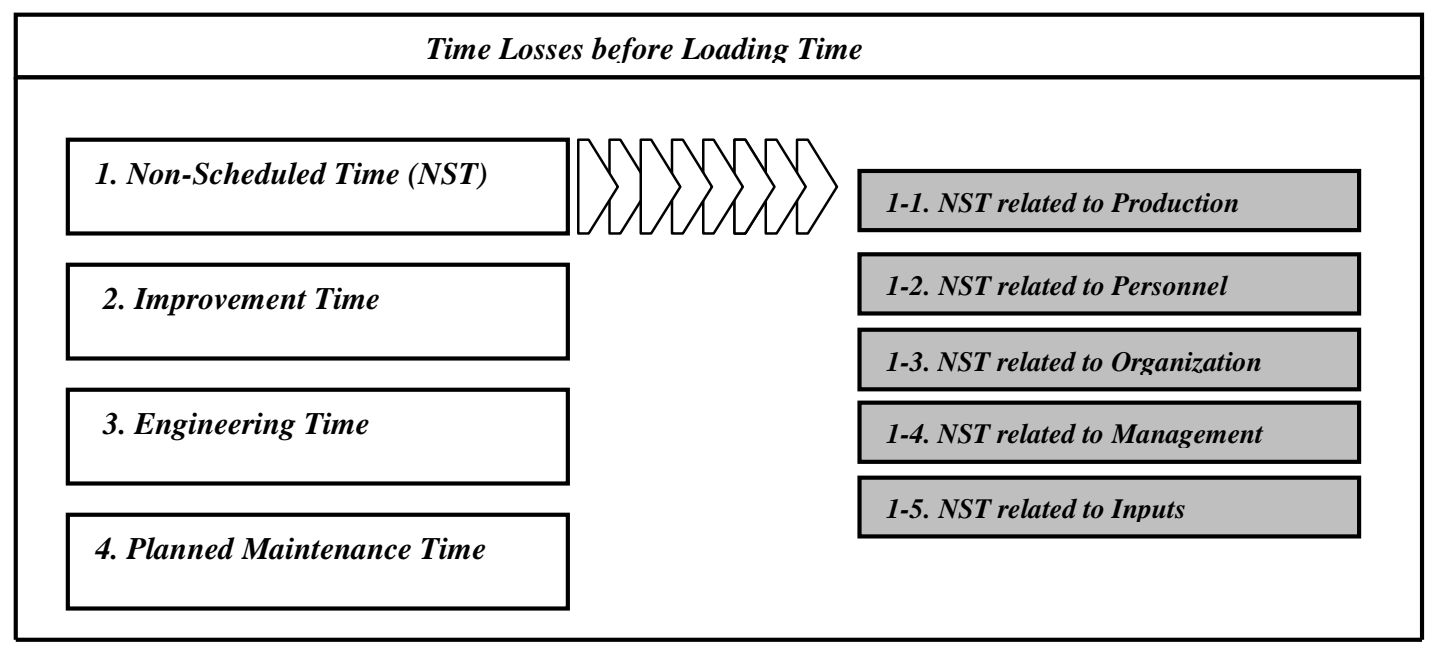

Figure 1. The losses ignored by OEE

Non-scheduled time related to production (NSTPro) includes all time spent on any disruption to the production schedule, time spent on carrying out current orders, general preparation and basic maintenance such as cleaning and lubrication.Non-scheduled time related to personnel (NSTPer) includes all time losses because of shortage of labour due to daily shop floor meetings, and training.Non-scheduled time related to organization (NSTOrg) includes non-operational time due to shift changing, and unscheduled time for holidays and night shifts. Non-scheduled time related to management (NSTMng) includes all time spent on precautionary periods.Non-scheduled time related to inputs (NSTInp) includes all non-operational time due to lack of material, electricity and utilities such as water.

Time spent on R\&D, and activities for upgrading plant, equipment and process which need no operation of machines is considered as another time loss before loading. It is referred as "Improvement Time". The two other losses are "Engineering Time" and "Planned Maintenance Time". These are described in detail by Anvari and Starr (2007) and Anvari, Edwards, and Starr (2008).

Because of high capital investment, steel companies should utilise equipment as effectively as they can and thus a new method for the precise calculation of the equipment utilisation is proposed. "Market Time" is a meaningful base to make a refined OEE which not only provides a sound frame for taking into consideration all losses which are actually effective but also reflects internal and external market changes and calculates effectiveness based on a wider capability to meet all market demands.

\section{Market Time (MT)}

As shown in Figure2, different machines and processes are arranged in a sequence of operations to manufacture the products in a continuous manufacturing system. The output of each machine may either be consumed as an input for a following machine or as an ultimate product to external customers, or a mixture of both. 


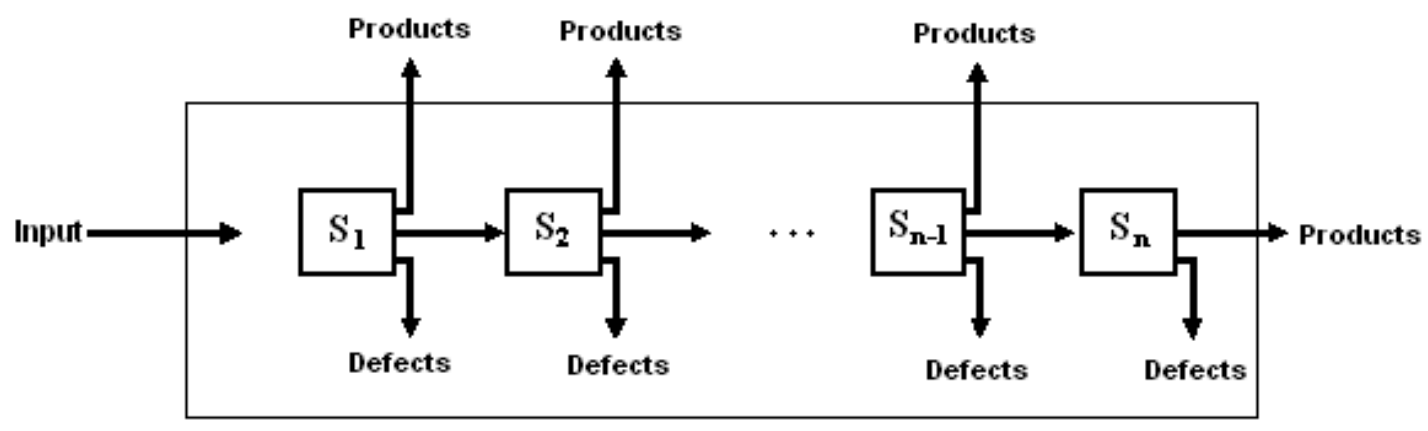

Figure 2. A continuous manufacturing system

The output of the first machine may be delivered to both external market and the second machine. Market Time $\left(\mathrm{MT}_{1}\right)$ for this machine means the time duration for producing products to satisfy external market demand $\left(\mathrm{ED}_{1}\right)$ and internal market demand $\left(\mathrm{ID}_{1}\right)$. This period includes the time spent on the defects of the machine $\left(\mathrm{D}_{1}\right)$ and breakdown losses $\left(\mathrm{BD}_{1}\right)$, setup and adjustment losses $\left(\mathrm{SA}_{1}\right)$ and minor stoppage $\left(\mathrm{MS}_{1}\right)$ for this machine too. The manufacturing rate is identified by unit per hour (UPH). The actual units per hour $\left(\mathrm{AUPH}_{1}\right)$ indicates the actual speed of machine number 1 .

The Market time for machine number $1\left(\mathrm{MT}_{1}\right)$ is calculated as given:

$\mathrm{MT}_{1}=\mathrm{ED}_{1} / \mathrm{AUPH}_{1}+\mathrm{D}_{1} / \mathrm{AUPH}_{1}+\mathrm{ID}_{1} / \mathrm{AUPH}_{1}+\mathrm{BD}_{1}+\mathrm{SA}_{1}+\mathrm{MS}_{1}$

where

$\mathrm{ID}_{1} / \mathrm{AUPH}_{1}=\mathrm{ED}_{2} / \mathrm{AUPH}_{2}+\mathrm{D}_{2} / \mathrm{AUPH}_{2}+\mathrm{ID}_{2} / \mathrm{AUPH}_{2}+\mathrm{BD}_{2}+\mathrm{SA}_{2}+\mathrm{MS}_{2}$

Where Market Time for machine number $2\left(\mathrm{MT}_{2}\right)$ is defined in terms of its characters including external market demand $\left(\mathrm{ED}_{2}\right)$, internal market demand $\left(\mathrm{ID}_{2}\right)$, defects $\left(\mathrm{D}_{2}\right)$, and actual units per hour

$\left(\mathrm{AUPH}_{2}\right)$.Therefore

$\mathrm{MT}_{1}=\mathrm{ED}_{1} / \mathrm{AUPH}_{1}+\mathrm{D}_{1} / \mathrm{AUPH}_{1}+\mathrm{ED}_{2} / \mathrm{AUPH}_{2}+\mathrm{D}_{2} / \mathrm{AUPH}_{2}+\mathrm{ID}_{2} / \mathrm{AUPH}_{2}+\mathrm{BD}_{1}+\mathrm{SA}_{1}+\mathrm{MS}_{1}+\mathrm{BD}_{2}+\mathrm{SA}_{2}+$ $\mathrm{MS}_{2}$

Similarly, Market Time for the second machine (MT2) is given by:

$\mathrm{MT}_{2}=\mathrm{ED}_{2} / \mathrm{AUPH}_{2}+\mathrm{D}_{2} / \mathrm{AUPH}_{2}+\mathrm{ED}_{3} / \mathrm{AUPH}_{3}+\mathrm{D}_{3} / \mathrm{AUPH}_{3}+\mathrm{ID}_{3} / \mathrm{AUPH}_{3}+\mathrm{BD}_{2}+\mathrm{SA}_{2}+\mathrm{MS}_{2}+\mathrm{BD}_{3}+\mathrm{SA}_{3}+$ $\mathrm{MS}_{3}$

and Market Time for the machine number N-1 (MTn-1) is calculated as given below:

$\mathrm{MT}_{\mathrm{n}-1}=\mathrm{ED}_{\mathrm{n}-1} / \mathrm{AUPH}_{\mathrm{n}-1}+\mathrm{D}_{\mathrm{n}-1} / \mathrm{AUPH}_{\mathrm{n}-1}+\mathrm{ED}_{\mathrm{n}} / \mathrm{AUPH}_{\mathrm{n}}+\mathrm{D}_{\mathrm{n}} / \mathrm{AUPH}_{\mathrm{n}}+\mathrm{ID}_{\mathrm{n}} / \mathrm{AUPH}_{\mathrm{n}}$ $+\mathrm{BD}_{\mathrm{n}-1}+\mathrm{SA}_{\mathrm{n}-1}+\mathrm{MS}_{\mathrm{n}-1}+\mathrm{BD}_{\mathrm{n}}+\mathrm{SA}_{\mathrm{n}}+\mathrm{MS}_{\mathrm{n}}$

Market Time may be used as a representation of all the losses which affect incurred equipment effectiveness. Therefore, it is necessary to specify which of the time losses arise within the Market Time. 


\section{Time losses within market time}

The Overall Equipment Effectiveness-Market Based (OEE-MB) estimation is used to calculate equipment effectiveness during market time. Market time means the time duration for producing products which have the market, internal and/or external, and can be sold. In other words,

Loading time $\leq \mathrm{MT} \leq$ Calendar time

If the total market demand, both internal and external, is more than the number of units produced, the time losses before the loading time should be analysed to specify losses with respect to market time. Among the all activities before the loading time, only those which are regarded as a loss when manufacturing within this time duration is still required to meet market need. The activities before the loading time are not considered as losses when the quantity of product manufactured is enough to satisfy market demand. In the cases where only some parts of the duration before the loading time are required to meet market requirement, all of those time losses should be ranked in the terms of how much they are avoidable. The easier avoidable losses should be considered as time losses before the harder avoidable ones until all assigned time is enough to respond to market demand.

In other words, as shown in Figure 1, there are eight time losses before loading time and they may be ranked in terms of their level to be avoidable. The label of " 1 " is placed for the losses which are the easiest ones and the label of " 8 " for the hardest ones to avoid.

The most avoidable loss=TLBL1

The least avoidable loss=TLBL8

8

All time losses before loading time are $\sum$ TLBLi . The elements of $\sum$ TLBLi make time losses within $\mathrm{i}=1$

market time ( $\sum$ TLWMT).

As described in next section, OEE-Loading Based (LB) is the original OEE which considers the losses within loading time, and OEE-Capital Based(CB) is a metric to consider all losses before and after loading time. Considering the time losses within market time ( $\sum$ TLWMT) in addition to time losses after loading time, a new metric for measuring equipment effectiveness may be defined. A global metric to estimate equipment effectiveness based on all effective losses for the duration of satisfying both internal customers, following processing machines, and external customers, the outer market for the current product. Details are shown in Figure 3. 
Figure 3. OEE-MB Methodology

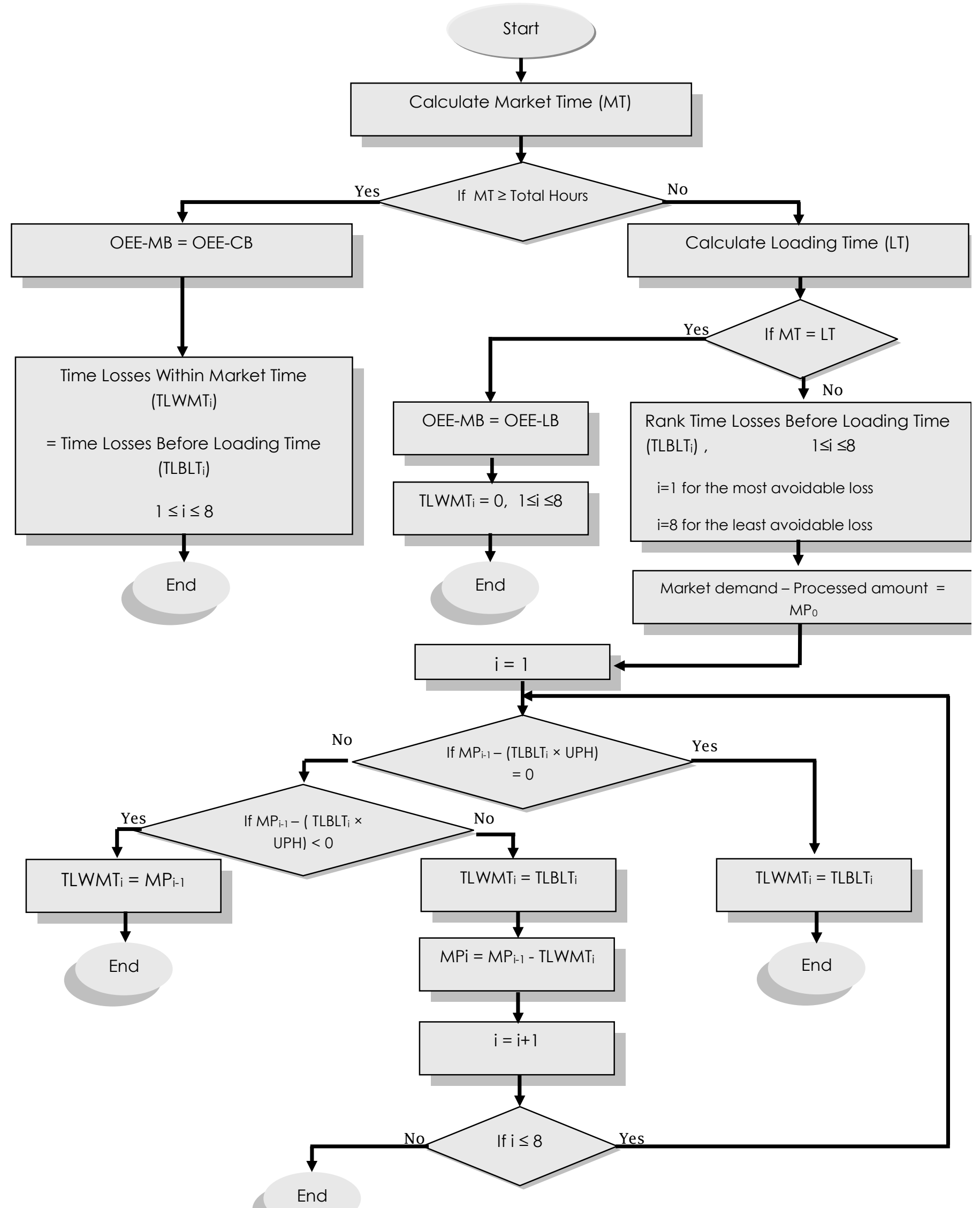




\section{OEE based on internal and external demand}

The OEE-MB estimation, as shown in Figure 4, is started to calculate the time losses from the market time.

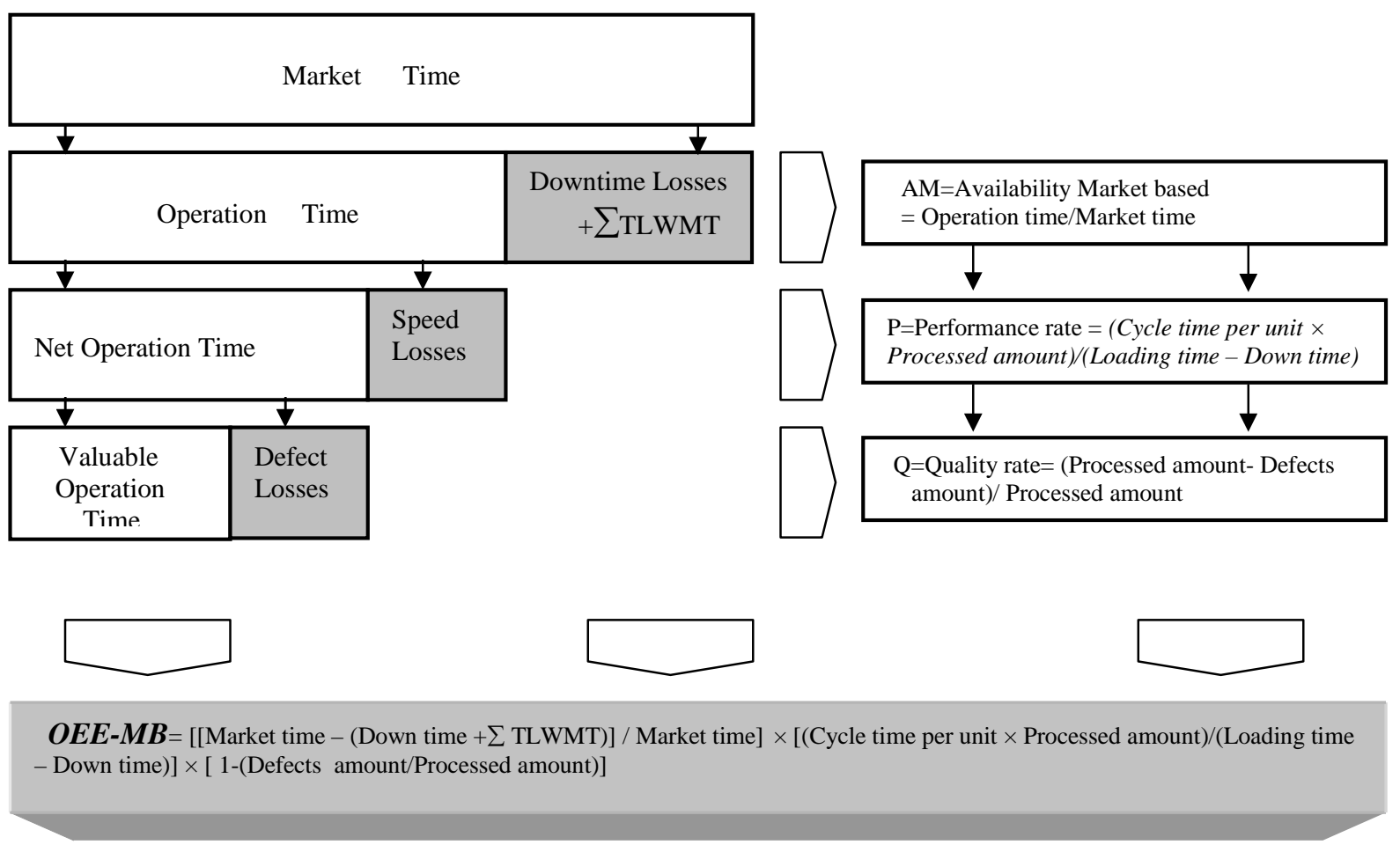

Figure 4. OEE-MB structure

As shown in Figure 3, Availability Market based (AM),Performance rate(P), and Quality rate(Q) are defined as given:

$\mathrm{AM}=\left[\right.$ Market time $-\left(\right.$ Down time $\left.\left.+\sum \mathrm{TLWMT}\right)\right] /$ Market time.

where

$\sum \mathrm{TLWMT}=$ the sum of all time losses within market time.

and

$\mathrm{P}=($ Cycle time per unit $\times$ Processed amount $) /($ Loading time - Down time $)$

and

$\mathrm{Q}=1-($ Defects amount/Processed amount).

Therefore OEE-MB can be calculated as given: 
OEE-MB $=\mathrm{AM} \times \mathrm{P} \times \mathrm{Q}=\left[\left(\right.\right.$ Market time $-\left(\right.$ Down time $+\sum$ TLWMT $\left.)\right) /$ Market time $] \times[($ Cycle time per unit $\times$ Processed amount)/(Loading time-Down time $)] \times[1-($ Defects amount/Processed amount $)]$

While MT tends towards the loading time, OEE-MB tends towards OEE-LB.OEE-LB, which is the original OEE, considers losses after loading time. While MT tends towards calendar time (total hours), OEE-MB tends towards OEE-CB. OEE-CB is a metric which considers all losses before loading time by ignoring market demands. These are described in detail by Anvari and Starr (2007) and Anvari, Edwards, and Starr (2008).

The concept of OEE-MB can be improved to make easier communications by developing OEE-MB tables and a colour coding approach for them.

\section{OEE-MB tables and colour coding}

The main purpose of an OEE-MB report is to make communications more efficient and to present essential data against which decisions may be made. Colour coding, applying a set of green, yellow and red indicators along with detailed measurements, is of assist in satisfying these needs." Traffic light" colour indicators are widely used in risk management, finance as well as maintenance. It makes OEEMB reports much easier to appreciate and improves the ability of management to quickly react to unacceptable situations. Tables for OEE-MB colour coded with green, yellow, and red indicators, perform as effective tools to prioritisation of activities to improve equipment efficiency regarding market aspects:

Green: Satisfactory situation

The process with respect to a specific loss is in control and an acceptable level of loss is achieved. No action is required.

Red: Critical situation

The process with respect to a specific loss is not in control and an unacceptable level of loss is achieved. Prompt action must be taken.

Yellow: Warning situation

The level of a specific loss is intermediate between green (satisfactory) and red (critical) situations. More control is required to prevent to go toward a red situation (Anvari, Edwards and Starr ,2008).

Units per hour (UPH) is of 4 options including actual units per hour (AUPH), planned units per hour (PUPH), best practice units per hour (BUPH) and theoretical units per hour (TUPH). Tables for OEEMB may be presented for each of the above speeds.

The following sections illustrate the idea with an example of compact strip manufacturing processes within the steel industry.

\section{A case study research- Data collection}

The industry selected for OEE-MB application is one of the leading steel making companies in Asia. The hot and cold rolled coils and sheets are supplied to regional and European markets. The selected machinery system is one the key machines. It was selected because data for it were comparatively easy accessible. This was a main criterion for selecting the case among all key machines.

Four types of forms were developed to gather required data including losses before and after loading time, different types of UPH, limitations for colour coded indicators and market specifications. 
Form A was developed to gather data about losses after loading time. Data on losses after loading was recorded by foremen and verified by the Technical Office. Computerised control system recorded some required items such as breakdowns and the rest obtained manually.

Form B was developed to gather data about losses before loading time. Data on losses before loading was recorded by foremen or the Technical Office and verified by management. Some data such as planned maintenance time obtained from Management Information System (MIS) and the rest obtained manually.

Form $\mathrm{C}$ was developed to gather data about the market, different types of UPH and limitations for colour coded indicators. Data was recorded by the Technical Office and verified by management. The computerised control system recorded some required items such as the best practise for UPH and the rest obtained manually.

Form D was developed to summarise monthly data about losses before and after loading time. This form was filled in by the Technical Office.

All data collected by the above forms were analysed in order to measure OEE-MB and to make relevant tables.

\section{Data analysis}

Data collected for the duration of three months and the researcher studied all data and asked more details or other information in case there was an element of ambiguity. All processed amount for total hours of 2184 was 144690.30 tonnes. Data summarised in Figure 5.

Different types of speed for the machine were given as:

PUPH $=97$ tonne/hour

BUPH $=107.3$ tonne/hour

TUPH $=116$ tonne/hour

The case did not operate at a constant speed, therefore AUPH was calculated as:

AUPH $=($ Processed amount + Defects $) /($ Total hours-Total time losses $)$

While the machinery system operated at actual speed of 90.15 tonne/hour, market demand was 160415 tonnes for the sum of the two sets of internal and external demand.

Time losses are categorised in Table 1 but reduced speed losses was obtained as given below:

Reduced speed losses=Processed amount $\times[(\mathrm{UPH} / \mathrm{AUPH})-1]$

All of the time losses before the loading time, as shown in Table 1, were ranked in the terms of how much they are avoidable .Considering all previous records and their history, the technical office ranked these losses based on the qualities and features that each of them has within the relevant manufacturing area. The easier avoidable losses are ranked before the harder avoidable ones. All the data was verified by plant management too. 


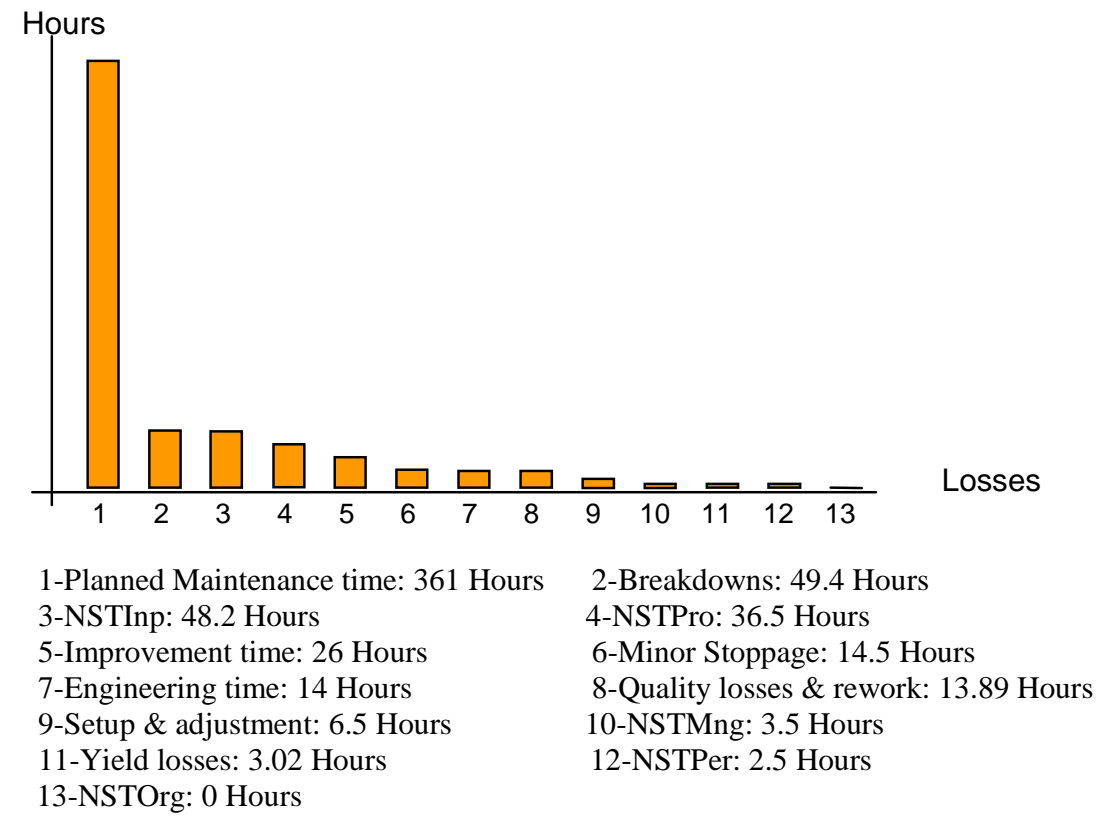

Figure 5. Time Losses for the machinery system over a three-month period

\begin{tabular}{|c|c|}
\hline $\begin{array}{l}\text { Ranking } \\
\text { from } \\
1 \text { to } 8 *\end{array}$ & $\begin{array}{l}\text { All time losses before loading time }\left(\sum \text { TLBL }\right) \\
\text { which may form time losses within market } \\
\text { time }\left(\sum \text { TLWMT) }\right.\end{array}$ \\
\hline 1 & $\begin{array}{l}\text { Non-scheduled time related to Organization } \\
\text { (NSTOrg) }\end{array}$ \\
\hline 2 & $\begin{array}{l}\text { Non-scheduled time related to Personnel } \\
\text { (NSTPer) }\end{array}$ \\
\hline 3 & $\begin{array}{l}\text { Non-scheduled time related to Management } \\
\text { (NSTMng) }\end{array}$ \\
\hline 4 & Improvement time \\
\hline 5 & Engineering time \\
\hline 6 & $\begin{array}{l}\text { Non-scheduled time related to Inputs } \\
\text { (NSTIn) }\end{array}$ \\
\hline 7 & $\begin{array}{l}\text { Non-scheduled time related to Production } \\
\text { (NSTPro) }\end{array}$ \\
\hline 8 & Planned Maintenance(PM) time \\
\hline
\end{tabular}

* 1 for the most avoidable loss 8 for the least avoidable loss

Table 1. Ranking table for losses before loading time

The amount of PM time for the period of research is considerable. Data gathering for the case study coincided with major PM activities of the plant according to the yearly PM plan. There is a need for investigating the other causes of the excessive PM time. A survey of the results including some details for the equipment is given in the next section. 


\section{A survey of the results}

The results of OEE-MB for AUPH, PUPH, BUPH, and TUPH are summarised in Tables 2 to 5 respectively.

\begin{tabular}{l}
\hline \multicolumn{3}{|c|}{ AUPH=90.15 tonnes per hour } \\
\begin{tabular}{|c|l|l|}
\hline OEE-MB=0.85 Effects & \multicolumn{1}{|c|}{ Lost units (Tonne) } & Percentage loss (\%) \\
\hline Time losses & 4453.41 & 18.87 \\
\hline Breakdown & 585.96 & 2.48 \\
\hline Setup \& adjustment & 1307.16 & 5.54 \\
\hline Minor stoppage & 0 & 0 \\
\hline Reduced Speed & 1252 & 5.31 \\
\hline Rework & 272 & 1.15 \\
\hline Yield & 3290.48 & 13.95 \\
\hline NST related to Production & 225.38 & 0.96 \\
\hline NST related to Personnel & 0 & 0 \\
\hline NST related to Organization & 315.52 & 1.34 \\
\hline NST related to Management & 4345.23 & 18.42 \\
\hline NST related to Inputs & 2343.9 & 9.93 \\
\hline Improvement Time & 1262.1 & 5.35 \\
\hline Engineering Time & 3942.10 & 16.71 \\
\hline Planned Maintenance & & \\
\hline
\end{tabular}
\end{tabular}

Table 2. OEE-MB Table for AUPH

\begin{tabular}{|c|c|c|}
\hline OEE-Market based $=0.79$ & \multicolumn{2}{|c|}{ PUPH= 97 tonnes per hour } \\
\hline Time losses $\quad$ Effects & Lost units (Tonne) & Percentage loss (\%) \\
\hline Breakdown & 4791.8 & 13.66 \\
\hline Setup\& adjustment & 630.5 & 1.80 \\
\hline Minor stoppage & 1406.5 & 4.01 \\
\hline Reduced Speed & 10994.22 & 31.35 \\
\hline Rework & 1252 & 3.57 \\
\hline Yield & 272 & 0.78 \\
\hline NST related to Production & 3540.5 & 10.10 \\
\hline NST related to Personnel & 242.5 & 0.69 \\
\hline NST related to Organization & 0 & 0 \\
\hline NST related to Management & 339.5 & 0.97 \\
\hline NST related to Inputs & 4675.4 & 13.33 \\
\hline Improvement Time & 2522 & 7.19 \\
\hline Engineering Time & 1358 & 3.87 \\
\hline Planned Maintenance & 3046.80 & 8.69 \\
\hline
\end{tabular}

Table 3. OEE-MB Table for PUPH 


\begin{tabular}{|c|l|l|}
\hline \multicolumn{2}{|c|}{ BUPH= 107. 3 tonnes per hour } \\
\hline Offects & \multicolumn{1}{|c|}{ Lost units (Tonne) } & Percentage loss (\%) \\
\hline Time losses & 5300.62 & 10.13 \\
\hline Breakdown & 697.45 & 1.33 \\
\hline Setup\& adjustment & 1555.85 & 2.97 \\
\hline Minor stoppage & 27525.66 & 52.60 \\
\hline Reduced Speed & 1252 & 2.39 \\
\hline Rework & 272 & 0.52 \\
\hline Yield & 3916.45 & 7.48 \\
\hline NST related to Production & 268.25 & 0.51 \\
\hline NST related to Personnel & 0 & 0 \\
\hline NST related to Organization & 375.55 & 0.72 \\
\hline NST related to Management & 5171.86 & 9.88 \\
\hline NST related to Inputs & 2789.8 & 5.33 \\
\hline Improvement Time & 1502.2 & 2.87 \\
\hline Engineering Time & 1700.59 & 3.25 \\
\hline Planned Maintenance & & \\
\hline
\end{tabular}

Table 4. OEE-MB Table for BUPH

OEE-Market based $=0.66 \quad$ UPH $=216$ tonnes per hour

\begin{tabular}{|c|l|l|}
\hline Time losses Effects & Lost units (Tonne) & Percentage loss (\%) \\
\hline Breakdown & 5730.4 & 8.57 \\
\hline Setup\& adjustment & 754 & 1.13 \\
\hline Minor stoppage & 1682 & 2.51 \\
\hline Reduced Speed & 41489.12 & 62.01 \\
\hline Rework & 1252 & 1.87 \\
\hline Yield & 272 & 0.41 \\
\hline NST related to Production & 4234 & 6.33 \\
\hline NST related to Personnel & 290 & 0.43 \\
\hline NST related to Organization & 0 & 0 \\
\hline NST related to Management & 406 & 0.61 \\
\hline NST related to Inputs & 5591.2 & 8.36 \\
\hline Improvement Time & 3016 & 4.51 \\
\hline Engineering Time & 1624 & 2.43 \\
\hline Planned Maintenance & 563.50 & 0.84 \\
\hline
\end{tabular}

Table 5. OEE-MB Table for TUPH 
For purpose of identifying the financial implications of losses, the market value of the product was about 578 euros per tonne for the period of the research.

The rows of above tables depend on their situation as satisfactory, warning and critical, come in a wide range of green, yellow and red colours. A sensitivity analysis can show whether changes in internal and/or external market demands will affect the amount of OEE-MB.

The results of the above tables for OEE and OEE-MB are summarised in Figure 6 as given :

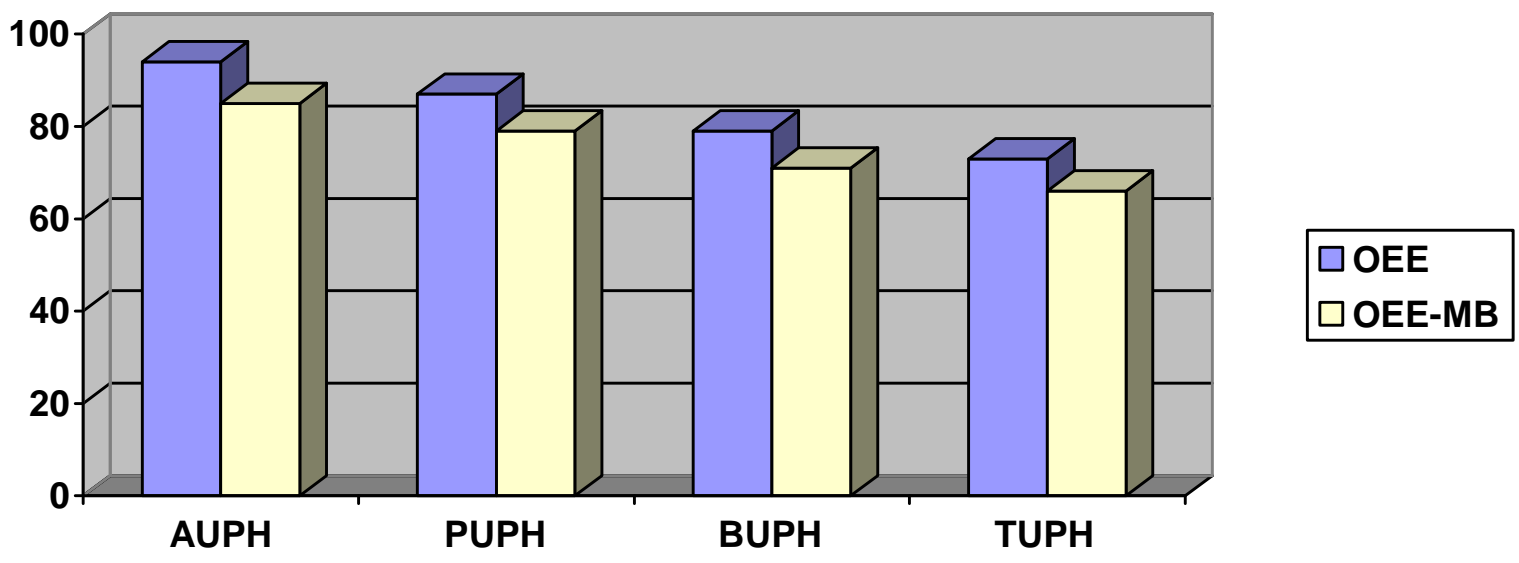

Figure 6. The difference between OEE and OEE-MB for a period over 3 months

\section{Sensitivity analysis}

The proposed model is measured overall effectiveness based on market and the amount of both internal and external demand. To identify how much a change in market is reflected in the amount of OEE-MB, the sensitivity analysis is used. Tables 6 and 7 show changes in OEE and OEE-MB respectively after $10 \%$ increase of market demands for AUPH, PUPH, BUPH and TUPH.

\begin{tabular}{l|cccc} 
& $\begin{array}{c}\text { AUPH } \\
90.15 \\
\text { Tonnes per hour }\end{array}$ & $\begin{array}{c}\text { PUPH } \\
97.00 \\
\text { Tonnes per hour }\end{array}$ & $\begin{array}{c}\text { BUPH } \\
107.30\end{array}$ & $\begin{array}{c}\text { TUPH } \\
116.00\end{array}$ \\
\hline Tnitial OEE & 0.94 & 0.87 & 0.79 & 0.73 \\
\hline $\begin{array}{l}\text { OEE after 10\% increase of } \\
\text { market demands }\end{array}$ & 0.94 & 0.87 & 0.79 & 0.73 \\
\hline $\begin{array}{l}\text { OEE after 10\% increase of } \\
\text { market demands / Initial OEE }\end{array}$ & 1 & & & 1 \\
\hline
\end{tabular}

Table 6. The effect of 10 percent increase in market demands for OEE 


\begin{tabular}{l|cccc} 
& $\begin{array}{c}\text { AUPH } \\
90.15 \\
\text { Tonnes per hour }\end{array}$ & $\begin{array}{c}\text { PUPH } \\
97.00 \\
\text { Tonnes per hour }\end{array}$ & $\begin{array}{c}\text { BUPH } \\
107.30\end{array}$ & $\begin{array}{c}\text { TUPH } \\
\text { Tonnes per hour }\end{array}$ \\
\hline Tnitial OEE-MB per hour \\
\hline
\end{tabular}

Table7. The effect of 10 percent increase in market demands for OEE-MB

The drop in OEE-MB reflects a change in market. While the total demand, internal and/or external, is increased, and the machinery system is in operation with the previous specifications, OEE-MB is decreased comparison with the previous amounts. The ratio of OEE-MB after $10 \%$ increase of market demands to initial OEE-MB is about 0.90. The table 6 shows, however, OEE does not reflect the changes in market.

\section{Conclusions and further work}

Based on a new scheme for loss analysis including lost units and percentage loss out of all losses within market time OEE-MB is proposed. Monitoring the process and precise measurement of its main aspects is the key step to plan and to manage improvement for a manufacturing process. In the steel industry OEE-MB monitors production and measures the equipment effectiveness for full process cycle in order to respond to the market. Also, it provides a sound perspective on production improvement of steel plants by taking into consideration all losses within the period for meeting both internal and external market demands. It may be used as a tool of improvement. While, the results for OEE by ignoring a considerable amount of possible hidden losses might be satisfying, the OEE-MB report shows potential room for improvement.

It reflects changes in both internal and external market for the steel industry, and therefore provides a tool for not only monitoring but also managing improvement.

The results of the case study show that the proposed method deploys the concept of equipment effectiveness clearer and more applicable. It makes communication more efficient and easier within the steel industry and may be used as a benchmark to achieve world-class standard.

OEE-MB was calculated over a three-month period. It is important to examine this method over a longer period and within more steel plants. As a step of applying the method, all of the time losses before the loading time should be ranked in the terms of how much they are avoidable. At present in its infancy, they are ranked based on the qualities and features that each of them has within the relevant manufacturing process by considering all previous records. A further work to develop a quantitative measure is of assist in analysing priority. 


\section{References}

Al-Najjar, B.(1996), "Total Quality Maintenance: An approach for continuous reduction in costs of quality products", Journal of Quality in Maintenance Engineering,Vol.2, Issue3,pp.4-20.

Al-Najjar, B.(1999),"Economic criteria to select a cost-effective maintenance policy”, Journal of Quality in Maintenance Engineering,Vol.5,Issue3, pp.236-248.

Anvari, F. and Starr, A.(2007)," New Trends and the Role of TPM", The 2nd World on Engineering Asset Management (EAM) and The 4th International Conference on Condition Monitoring, Harrogate, United Kingdom,11-14 June 2007,pp. 164-173 .

Anvari, F., Edwards, R., and Starr, A.(2008)," Integrated Equipment Effectiveness", The 3rd World Congress on Engineering Asset Management (EAM) and The $5^{\text {th }}$ International Conference on Condition Monitoring, Edinburgh, United Kingdom,15-18 July 2008,pp. 56-64 .

Bamber, C.J. et al., (2003),"Cross-functional team working for overall equipment effectiveness (OEE)" , Journal of Quality in Maintenance Engineering, Vol. 9, Issue 3, pp. 223 - 238.

Dal, B., Tugwell, P. and Greatbanks, R.(2000),”Overall equipment effectiveness as a measure of operational improvement, a practical analysis", International Journal of Operations and Production Management, Vol. 20, Issue12, pp. 1488-1502.

Gibbons, P.M.(2006),” Improving overall equipment efficiency using a Lean Six Sigma approach", International Journal of Six Sigma and Competitive Advantage, Vol. 2, No.2,pp. 207 - 232.

Hansen, R.C.(2001),”Overall equipment effectiveness-A powerful production maintenance tool for increased profits", Industrial Press Inc.

Jeong K.Y. and Phillips D.T.(2001),'Operational efficiency and effectiveness measurement”, International Journal of Operations \& Production Management, Vol. 21, No. 11, pp. 1404-1416.

Ljungberg, O. (1998),'Measurement of overall equipment effectiveness as a basic for TPM activities", International Journal of Operations and Production Management, Vol. 18,No.5, pp. 495-507.

Nachiappan, R.M. and Anantharaman, R.M. (2006),"Evaluation of overall line effectiveness in a continuous product line manufacturing system", Journal of Manufacturing Technology Management, 17, pp.9871008 .

Nakajima, S. (1988),'Introduction to TPM”, Productivity Press ,Cambridge, MA.

Peters, R.W.(2003),'Measuring overall craft effectiveness: are you a takeover target for contract maintenance, Plant Engineering, Vol. 57,No.10, pp.39-41.

Raouf,A.(1994),'Improving capital productivity through maintenance” ,International Journal of Operations and Production Management,Vol.14,No.7, pp. 44-52.

Ron, A.J. de and Rooda, J.E. (2005),'Equipment effectiveness: OEE revisited", IEEE transactions on semiconductor manufacturing, Vol. 18, No.1, PP 190-196.

Tajiri, M. and Gotoh, F. (1992),’TPM implementation-a Japanese approach”, McGraw-Hill. 


\section{About the authors}

Farhad Anvari is a PhD student in the School of Mechanical, Aerospace and Civil Engineering, The University of Manchester. He has worked more than fifteen years in the steel industry .He is the corresponding author and can be contacted at: farhad.anvari@postgrad.manchester.ac.uk .

Dr. Rodger Edwards is a Senior Lecturer in the School of Mechanical, Aerospace and Civil Engineering, The University of Manchester. He is a chartered engineer and has over 25 years of research experience in the areas of Building Services, Energy and other engineering disciplines.

Professor Andrew Starr is a Professor of Mechanical Engineering in The University of Hertfordshire. His work spans the spectrum of problem solving in maintenance, including systems analysis, failure modes, measurement techniques such as vibration and wear debris, automation of processing, decisionmaking mathematics, and management processes. 